\title{
Hearing loss in Pompe disease revisited: results from a study of 24 children
}

\author{
Carine I. van Capelle • Andre Goedegebure • \\ Nienke C. Homans • Hans L. J. Hoeve • \\ Arnold J. Reuser • Ans T. van der Ploeg
}

Received: 8 April 2010 /Accepted: 26 May 2010 /Published online: 2 July 2010

(C) The Author(s) 2010. This article is published with open access at Springerlink.com

\begin{abstract}
Little information is available regarding the auditory function in Pompe patients. Hearing loss has been reported in classic infantile patients, but it is still unknown whether central nervous system involvement interferes with auditory function and whether enzyme replacement therapy can improve hearing. Auditory function has not been studied in children with milder forms of the disease. We analyzed repetitive auditory brainstem response measurements and pure tone audiometry in 24 children with Pompe disease. Only 1 of 13 patients with milder phenotypes showed recurrent conductive hearing loss, while 10 out of 11 classic infantile patients had sensorineural hearing defects. These patients also had a high prevalence of conductive hearing loss. Five patients showed evidence of mild retrocochlear pathology, suggestive of glycogen accumulation in the central nervous system. Hearing loss persisted during therapy in all patients. The results emphasize the need for careful monitoring of auditory function in classic infantile Pompe patients, and for early implementation of hearing aids to protect speech and language development.
\end{abstract}

Communicated by: Ed Wraith

C. I. van Capelle $\cdot$ A. T. van der Ploeg $(\bowtie)$

Department of Pediatrics, Division of Metabolic Diseases and Genetics, Center for Lysosomal and Metabolic Diseases, Erasmus MC University Medical Center-Sophia Children's Hospital, Postbus 2060,

3000 CB Rotterdam, the Netherlands

e-mail: a.vanderploeg@erasmusmc.nl

A. Goedegebure $\cdot$ N. C. Homans $\cdot$ H. L. J. Hoeve

Department of Otorhinolaryngology, Erasmus MC University

Medical Center-Sophia Children's Hospital,

Rotterdam, The Netherlands

C. I. van Capelle • A. J. Reuser

Department of Clinical Genetics, Center for Lysosomal and Metabolic Diseases, Erasmus MC University Medical Center, Rotterdam, The Netherlands

\section{Introduction}

Hearing deficits have been found in several lysosomal storage disorders including Gaucher disease (Bamiou et al. 2001; Kaga et al. 1982; Lacey and Terplan 1984)), Fabry disease (Hajioff et al. 2006; Hegemann et al. 2006; Keilmann et al. 2009; Palla et al. 2007; Schachern et al. 1989), and Mucopolysaccharidoses (Komura et al. 1998; Peck 1984; Schachern et al. 2007). Previously, we have detected hearing loss in four classic infantile Pompe patients as a new finding (Kamphoven et al. 2004).

Pompe disease (also called glycogen storage disease type II or acid maltase deficiency) (OMIM 232300) is caused by deficiency of the lysosomal enzyme acid alpha-glucosidase (EC 3.2.1.20). This leads to progressive glycogen storage in several tissues, among which skeletal and cardiac muscle are the most important (van der Ploeg and Reuser 2008; Engel et al. 2004). The disease occurs in infants, children, and adults with a variable degree of disease severity and progression of muscle weakness. The clinical condition of patients with the so-called classic infantile form rapidly deteriorates, leading to death before the age of 1 year (van den Hout et al. 2003; Kishnani et al. 2006). Patients with other phenotypes show a more slowly progressive disease course (Winkel et al. 2005). In the past, no treatment other than supportive care was available, but the recent introduction of enzyme replacement therapy has changed the prospect for patients (Kishnani et al. 2007, 2009; Strothotte et al. 2009; van Capelle et al. 2008; Van den Hout et al. 2004).

Although hearing loss is now increasingly recognized in classic infantile patients, the exact prevalence and type of hearing loss has never been investigated in a large group of patients, especially not in patients with more slowly progressive forms of the disease.

In this study, we analyzed repetitive auditory brainstem response measurements (ABRs) and pure tone audiometries before and after start of enzyme therapy in a cohort of 24 
children: 11 patients with the classic infantile form and 13 patients with a less severe, juvenile form of the disease.

\section{Patients and methods}

\section{Subjects}

Twenty-four patients, 11 classic infantile and 13 juvenile patients, were enrolled in the present study. All patients were diagnosed with Pompe disease by detecting enzyme deficiency in leukocytes or fibroblasts, and by mutation analysis. Inclusion criteria for the infantile group were: symptoms of muscle weakness within 3 months after birth, hypertrophic cardiomyopathy at diagnosis, and severe GAA (the gene encoding acid $\alpha$-glucosidase) mutations on both alleles. Inclusion criteria for the juvenile group were: all other children with Pompe disease having one GAA mutation on each allele, at least one of which not severe. Eleven of the juvenile patients and all classic infantile patients were enrolled in a prospective study investigating the safety and efficacy of enzyme replacement therapy with recombinant human acid $\alpha$-glucosidase $(20-40 \mathrm{mg} / \mathrm{kg}$ ). The other two juvenile patients were diagnosed presymptomatically, and were enrolled in an observational study that monitored disease progression in untreated patients. Both studies were approved by the Institutional Review Board of the Erasmus Medical Center, and all patients and parents gave written informed consent. All hearing assessments were performed before start of enzyme therapy and at regular intervals thereafter, if applicable.

\section{Hearing assessments}

In the juvenile patients, routine pure-tone audiometry was performed. When abnormalities were detected, the test was repeated at regular intervals, and patients were seen by an ENT (ear, nose and throat) specialist.

In the classic infantile patient group, auditory brainstem evoked responses, oto-acoustic emissions, and impedance audiometry were performed before the start of treatment and at regular intervals thereafter. An experienced audiologist evaluated the test results.

\section{Auditory tests}

Pure tone audiograms were made with a Madsen OB 822 audiometer (Copenhagen, Denmark) in a sound-proof room. Pure-tone threshold testing was performed for both air conduction and bone conduction. The average hearing threshold at frequencies $500,1,000,2,000$, and $4,000 \mathrm{~Hz}$ was used to classify the type of hearing loss (conductive component in case of an air-bone gap $>15 \mathrm{~dB}$ ) and to grade the amount of hearing loss according to the WHO definition of hearing impairment (WHO 1980).

Auditory brainstem evoked responses were determined using the Euphra-1 system and a Jaeger-Toennies preamplifier. Click stimuli were presented at different levels with a repetition rate of $23 / \mathrm{s}$ via a TDH 49 headphone. The waveform was analyzed by an experienced audiologist, defining peak latencies of waves I (distal cochlear part of the VIIIth nerve), III (in between cochlear nucleus and the superior olivary complex), and $\mathrm{V}$ (between the superior olivary complex and the inferior colliculus). The amount of hearing loss was estimated from the detection threshold of peak V. The time interval between peaks I, III, and V at stimulus level of $90 \mathrm{~dB}$ was used to identify retrocochlear dysfunction.

To assess cochlear function, transient evoked otoacoustic emissions (OAE) were carried out using the ILO288 (Otodynamics, UK). Otoacoustic emissions are vibrations presumably produced by the outer hair cells in the cochlea. Presence of otoacoustic emissions indicates a normal reponse to auditory stimuli of the middle ear and cochlea. To assess middle ear function, impedance audiometry was performed with a standard clinical impedance meter (AT260; Interacoustics, USA). An abnormal result indicates middle ear dysfunction.

The origin of the hearing deficit (conductive, cochlear, retrocochlear) was estimated by the combined interpretation of the ABR, otoacoustic emissions, and impedance audiometry.

\section{Statistical analysis}

ABR waveform latencies and inter-peak time intervals were compared to reference values obtained in 150 children with normal hearing in the Erasmus MC Sophia Children's hospital, and were expressed as z-scores. A z-score represents the number of standard deviations from the mean. Waveform latencies and inter-peak time intervals were considered abnormal if the measured value was above a z-score of 1.96. The individual relationship between the different outcome measures and treatment time were analyzed using least-squares regression.

All data analyses were performed using SPSS for Windows version 15 .

\section{Results}

Classic infantile Pompe patients

\section{Hearing loss}

Eleven classic infantile Pompe patients were included in the present study. Table 1 summarizes the clinical features of each of the patients. Table 2 tabulates the type of hearing 
loss found in each individual patient before start of treatment and after 1-6 years of treatment. Hearing loss was detected immediately after birth in some patients. There was no significant correlation between the age of the patients at their first hearing test and the severity of hearing loss. Baseline measurements were performed before start of enzyme therapy and revealed a sensorineural hearing loss in 9 of the 11 patients (for details, see Table 2). In all these patients, latencies of peaks I and $\mathrm{V}$ as function of stimulus level suggested a cochlear origin of the hearing loss. Absent OAEs with normal middle ear function confirmed the cochlear dysfunction in 6 patients, while abnormal tympanograms prohibited a reliable interpretation of the OAE results in 2 patients. Two patients had normal cochlear function but showed evidence of retrocochlear pathology, as inter-peak latencies between waves $\mathrm{I}$ and $\mathrm{V}$ were significantly prolonged.

Ten patients were followed for a maximum period of 6 years. One patient died at the age of 8 months. During the period that patients received enzyme therapy, the sensorineural hearing loss persisted in all with the exception of one patient, who had normal hearing at baseline. In addition, variable degrees of conductive hearing loss ranging from 15 to $60 \mathrm{~dB}$ were repeatedly found in nine patients (Fig. 1). Insertion of ventilation tubes in two patients did not improve their hearing levels. All patients (except patient 8 ) received hearing aids and/or speech therapy.

\section{Neurological involvement}

Waves I, III, and V were identified in all patients. Baseline nerve conduction patterns appeared to be close to normal for most of the patients. Inter-peak latency between peak I and peak V (IPL $\mathrm{I}_{\mathrm{I}-\mathrm{V}}$ ) was prolonged in 3 patients (Table 2 , patients 6,8 , and 9 ).

During follow-up assessments, $\mathrm{IPL}_{\mathrm{I}-\mathrm{V}}$ remained prolonged in these three patients. Two other patients, who both had normal values at baseline, showed prolongation of $\mathrm{IPL}_{\mathrm{I}-\mathrm{V}}$ at the age of 1.5 years (patients 3 and 7). One of these patients started receiving enzyme therapy in the first month of life, the other at the age of 8 months when she was in an end stage of the disease. In both patients, IPL $L_{\mathrm{I}-\mathrm{V}}$ remained prolonged during the entire follow-up period. Further examination showed that a prolongation of the inter-peak latency was mainly found between peaks III and V.

\section{Juvenile Pompe patients}

Age of the patients at their baseline hearing test ranged from 3 to 16.4 years (mean 11.4). Age at first symptoms ranged from 6 months to 10 years, and age at diagnosis ranged from 0.8 to 11.6 years. Patient characteristics are presented in Table 3.

Pure-tone audiometry showed conductive hearing losses in patients 2 and 5 . No hearing deficits were found in the other patients. Patient 2 had a mild unilateral conductive hearing loss of $33.3 \mathrm{~dB}$. This patient exhibited mobility problems in early childhood, and was diagnosed with Pompe disease at the age of 3.5 years. At the age of 6 years, his auditory function was measured for the first time. At that moment, the patient was able to walk, and his pulmonary function was within normal limits. During followup examinations, the conductive hearing loss subsided, and test results became normal.

Patient 5 showed mild bilateral hearing loss during the first assessment in our hospital, at the age of 13 years. The patient was diagnosed with Pompe disease at the age of

Table 1 Characteristics of 11 classic infantile Pompe patients

\begin{tabular}{|c|c|c|c|c|c|}
\hline Patient & $\begin{array}{l}\text { Age first } \\
\text { assessment (months) }\end{array}$ & Gender $(\mathrm{M} / \mathrm{F})$ & Motor status at first assessment & $\begin{array}{l}\text { Motor status at } \\
\text { final assessment }\end{array}$ & $\begin{array}{l}\text { Age at final } \\
\text { ABR (years) }\end{array}$ \\
\hline 1 & 3 & M & Axial hypotonia, head-lag, extremity movement + & Walks unsupported & 6 \\
\hline 2 & 7 & $\mathrm{~F}$ & Paralysis legs, paresis arms & Tetraplegic & 6 \\
\hline 3 & 8 & F & Paralysis legs, paresis arms & Tetraplegic & 2 \\
\hline 4 & 2.5 & $\mathrm{~F}$ & Axial hypotonia, head-lag, extremity movement $+/-$ & Sits unsupported, $\uparrow 4.2$ years & 4 \\
\hline 5 & 2 & M & Axial hypotonia, head-lag, extremity movement + & Walks unsupported, $† 4.2$ years & 4 \\
\hline 6 & 1 & M & Axial hypotonia, head-lag, extremity movement + & Walks unsupported & 5 \\
\hline 7 & 0.5 & $\mathrm{~F}$ & Axial hypotonia, head-lag, extremity movement + & Walks unsupported & 5 \\
\hline 8 & 0.1 & M & Axial hypotonia, head-lag, extremity movement + & Walks unsupported & 3 \\
\hline 9 & 2 & M & Axial hypotonia, head-lag, extremity movement $+/-$ & Sits unsupported & 3 \\
\hline 10 & 0.2 & $\mathrm{~F}$ & Axial hypotonia, head-lag, extremity movement + & Walks unsupported & 1 \\
\hline 11 & 3.5 & F & Axial hypotonia, head-lag, extremity movement $+/-$ & No gains, $† 8$ months & - \\
\hline
\end{tabular}

$A B R$ Auditory brainstem response

$\dagger$ Died 
Table 2 Summary of audiometric results of the 11 classic infantile patients at baseline and after a maximum period of 6 years of enzyme replacement therapy with recombinant human $\alpha$-glucosidase

\begin{tabular}{|c|c|c|c|c|c|c|c|c|c|c|c|}
\hline \multirow[t]{2}{*}{ Patient } & \multirow[t]{2}{*}{ Age } & \multicolumn{5}{|c|}{ Right ear } & \multicolumn{5}{|c|}{ Left ear } \\
\hline & & EHT & Tymp & OAE & $\mathrm{I}-\mathrm{V}$ & III-V & EHT & Tymp & OAE & $\mathrm{I}-\mathrm{V}$ & III-V \\
\hline \multicolumn{12}{|c|}{ Baseline } \\
\hline 1 & $3 \mathrm{~m}$ & 30 & Normal & Absent & Normal & N.A. & 60 & Normal & Absent & Normal & N.A. \\
\hline 2 & $7 \mathrm{~m}$ & 70 & Normal & Absent & Normal & N.A. & 90 & Abnormal & Absent & Normal & N.A. \\
\hline 3 & $8 \mathrm{~m}$ & 40 & Normal & Absent & Normal & N.A. & 40 & Normal & Absent & Normal & N.A. \\
\hline 4 & $2.5 \mathrm{~m}$ & 40 & Abnormal & Absent & Normal & N.A. & 60 & Abnormal & Absent & Normal & N.A. \\
\hline 5 & $2 \mathrm{~m}$ & 80 & Normal & Absent & Normal & N.A. & 60 & Normal & Absent & Normal & N.A. \\
\hline 6 & $1 \mathrm{~m}$ & 20 & Normal & Present & Prolonged & 2.2 & 20 & Normal & Present & Prolonged & 2.7 \\
\hline 7 & $0.5 \mathrm{~m}$ & 50 & Normal & Absent & Normal & N.A. & 40 & Normal & Absent & Normal & N.A. \\
\hline 8 & $0.1 \mathrm{~m}$ & 10 & Normal & Present & Prolonged & 3.6 & 10 & Normal & Present & Prolonged & 2.5 \\
\hline 9 & $2 \mathrm{~m}$ & 60 & $?$ & $?$ & Prolonged & 3.3 & 60 & Normal & Absent & Normal & N.A. \\
\hline 10 & $2.5 \mathrm{~m}$ & 40 & Normal & Absent & Normal & N.A. & 40 & Normal & Absent & Normal & N.A. \\
\hline 11 & $3.5 \mathrm{~m}$ & 70 & Abnormal & Absent & Normal & N.A. & 70 & Abnormal & Absent & Normal & N.A. \\
\hline \multicolumn{12}{|c|}{ After maximum 6 years of enzyme replacement therapy } \\
\hline 1 & $6 \mathrm{y}$ & 80 & Abnormal & Absent & Normal & N.A. & 80 & Abnormal & Absent & Normal & N.A. \\
\hline 2 & $6 y$ & 70 & Normal & Absent & Normal & N.A. & 70 & Normal & Absent & Normal & N.A. \\
\hline 3 & $2 \mathrm{y}$ & 60 & Abnormal & Absent & Prolonged & 2.3 & 80 & Abnormal & Absent & Prolonged & 3.3 \\
\hline 4 & $4 y$ & 80 & Abnormal & Absent & Normal & N.A. & 90 & Abnormal & Absent & Normal & N.A. \\
\hline 5 & $4 \mathrm{y}$ & 80 & Normal & Absent & Normal & N.A. & 90 & Abnormal & Absent & Normal & N.A. \\
\hline 6 & $5 \mathrm{y}$ & 40 & Abnormal & Absent & Prolonged & 2.3 & 50 & Abnormal & Absent & Prolonged & 3.4 \\
\hline 7 & $5 \mathrm{y}$ & 70 & Abnormal & Absent & Prolonged & 2.2 & 50 & Abnormal & Absent & Prolonged & 1.0 \\
\hline 8 & $3 y$ & 20 & Normal & Present & Prolonged & 2.3 & 20 & Normal & Present & Prolonged & 2.3 \\
\hline 9 & $3 y$ & 80 & Abnormal & Absent & Prolonged & 2.3 & 80 & Abnormal & Absent & Prolonged & 2.9 \\
\hline 10 & $1 \mathrm{y}$ & 40 & Abnormal & Absent & Normal & N.A. & 40 & Abnormal & Absent & Normal & N.A. \\
\hline 11 & died & & & & & & & & & & \\
\hline
\end{tabular}

$m$ Months, $y$ years, EHT estimated hearing threshold (dB HL, decibels hearing level), Tymp tympanogram result, OAE otoacoustic emission result, $I-V$ auditory brainstem response inter-peak interval I to $\mathrm{V}, I I I-V$ auditory brainstem response inter-peak interval III to $\mathrm{V}$ (data are represented by z-scores, $>1.96$ is considered abnormal), N.A. not applicable

2 years. In the following years, she followed a rapidly progressive disease course, became completely wheelchair bound, and was invasively ventilated at the age of 6 . Severe weakness of the facial muscles caused dysarthria and dysphagia, for which she received feeding by percutaneous endoscopic gastroscopy tube. There was a medical history of persistent otitis media, for which she had received ventilation tubes at the age of 3 years. Additional examinations revealed a recurrent bilateral otitis media, and the hearing loss of $35 \mathrm{~dB}$ persisted during follow-up assessments.

\section{Discussion}

The present study confirms our previous finding that hearing disorders are a major concern in patients with the classic infantile form of Pompe disease (Kamphoven et al. 2004). These problems are rarely found in children with milder forms of the disease. The reason why hearing loss

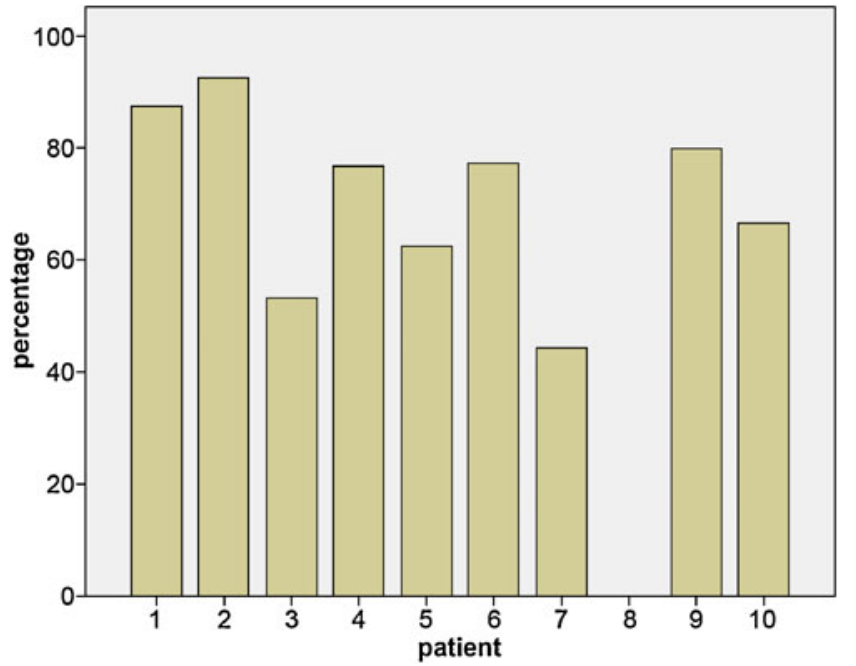

Fig. 1 Percentage of auditory brainstem responses (ABR) in which conductive hearing losses were found per patient. The number of ABRs performed per patients ranged from 1 (patient died at 5 months of age) to 18 and was on average 9 
Table 3 Characteristics of 13 children with Pompe disease, and the amount of hearing loss

\begin{tabular}{|c|c|c|c|c|c|c|}
\hline \multirow[t]{2}{*}{ Patient } & \multirow{2}{*}{$\begin{array}{l}\text { Age at hearing } \\
\text { test (years) }\end{array}$} & \multirow[t]{2}{*}{ Gender $(\mathrm{M} / \mathrm{F})$} & \multirow[t]{2}{*}{ Motor status $^{\mathrm{a}}$} & \multirow{2}{*}{$\begin{array}{l}\text { Respiratory } \\
\text { function }^{\mathrm{a}}\end{array}$} & \multicolumn{2}{|c|}{ Hearing loss $(\mathrm{dB})^{\mathrm{a}}$} \\
\hline & & & & & (right ear) & (left ear) \\
\hline 1 & 13.1 & M & Ambulant, prox weak & Normal & $\mathrm{nh}$ & $\mathrm{nh}$ \\
\hline 2 & 6.0 & M & Ambulant, prox weak & Normal & 33.3 cond & $\mathrm{nh}$ \\
\hline 3 & 12.7 & $\mathrm{~F}$ & Ambulant, prox weak & Diminished & $\mathrm{nh}$ & $\mathrm{nh}$ \\
\hline 4 & 11.9 & M & Partially wheelchair dep. & Normal & $\mathrm{nh}$ & $\mathrm{nh}$ \\
\hline 5 & 12.7 & $\mathrm{~F}$ & Tetraplegic & Invasive ventilation & 35 cond & 35 cond \\
\hline 6 & 5.2 & M & Ambulant & Normal & $\mathrm{nh}$ & $\mathrm{nh}$ \\
\hline 7 & 3 & M & Ambulant, prox weak & Normal & $\mathrm{nh}$ & $\mathrm{nh}$ \\
\hline 8 & 16 & M & Ambulant & Diminished & $\mathrm{nh}$ & $\mathrm{nh}$ \\
\hline 9 & 13 & M & Ambulant, prox weak & Diminished & $\mathrm{nh}$ & $\mathrm{nh}$ \\
\hline 10 & 9 & $\mathrm{~F}$ & Ambulant, prox weak & Normal & $\mathrm{nh}$ & $\mathrm{nh}$ \\
\hline 11 & 15.2 & M & Ambulant, prox weak & Diminished, BIPAP & $\mathrm{nh}$ & $\mathrm{nh}$ \\
\hline 12 & 16.4 & $\mathrm{~F}$ & Paresis legs, scoliosis & Diminished, BIPAP & $\mathrm{nh}$ & $\mathrm{nh}$ \\
\hline 13 & 9.2 & $\mathrm{~F}$ & Partially wheelchair dep. & Diminished, BIPAP & $\mathrm{nh}$ & $\mathrm{nh}$ \\
\hline
\end{tabular}

$d B$ Decibels, $n h$ normal hearing, cond conductive hearing loss, prox weak proximal weakness, BIPAP bi-level positive airway pressure

${ }^{\mathrm{a}}$ Before start of enzyme replacement therapy

selectively occurs in classic infantile patients is not fully understood, but may be explained by the less severe mutations and higher levels of residual $\alpha$-glucosidase activity in juvenile patients.

The hearing deficits that we detected in 10 of 11 classic infantile patients ranged from 30 to $90 \mathrm{~dB}$. As reported earlier, cochlear dysfunction was frequently found. But we also discovered additional conductive hearing losses in $75 \%$ of all hearing tests performed (in $90 \%$ of the patients). This is suggestive of chronic middle ear dysfunction. The etiology of chronic otitis media is multifactorial, and includes infectious, allergic, and immunologic factors resulting in Eustachian tube dysfunction and middle ear effusion (Mathew et al. 2007; Tos 1998). Our patients did not have clinical evidence for allergic or infectious middle ear problems, but we found severe weakness of the facial muscles in all classic infantile patients (Jones et al. 2009, and personal communication). The tensor veli palatini muscle is the principal muscle involved in opening the Eustachian tube. Weakness of this muscle has been reported to cause a pressure drop in the middle ear and may very well be the cause of the high incidence of conductive hearing loss found in infantile patients with Pompe disease.

To elucidate whether retrocochlear pathology was present in our classic infantile patient group, we studied repetitive ABRs. We found prolongation of inter-peak latencies in five patients. The most frequent finding was prolongation between peaks III and V. This is suggestive for pathology of the central part of the auditory pathway.

It was anticipated that glycogen storage in the brain and other parts of the central nervous system might cause sensorineural hearing loss (Kamphoven et al. 2004), since glycogen storage has been found in nuclei of the brain stem, thalamus, anterior horn cells, and neurons of the spinal ganglia. Glycogen storage was also reported to be present in several parts of the brain of a patient that died during treatment with enzyme therapy. This finding was not unexpected since the intravenously administered enzyme cannot pass the blood-brain barrier (Thurberg et al. 2006). Of note, three of the five patients with a prolongation of the inter-peak wave latencies belonged to the best responders to enzyme therapy. They were able to walk and had adequate cognitive abilities. Compared to other lysosomal storage disorders, like Gaucher type 3, the abnormalities in interpeak latencies were relatively mild. It is therefore suggested that glycogen storage, although undoubtedly present in brains of infants with Pompe disease, only minimally interferes with auditory functioning.

Hearing deficits were present shortly after birth. The extent of hearing loss did not decrease over time. This suggests that storage of glycogen in the cochlea already commences during gestation and that enzyme therapy does not have an effect on it. It should be noted, however, that there were variable degrees of conductive hearing loss, which interfered with the test results and prevented us from estimating the exact degree of sensorineural hearing loss.

In conclusion, our data emphasize that hearing problems are a major concern for patients with classic infantile Pompe disease, and are only sporadically present in children with milder forms of the disease. We therefore advise the monitoring of auditory function on a regular basis in infants with the disease, while regular examinations 
of auditory function are not required in older children. Retrocochlear pathology may be present, but does not seem to be a major contributor to the hearing problems. In addition to the previously reported cochlear hearing loss in infants, we found frequent conductive hearing losses in our patients. It is our experience that insertion of ventilation tubes does not consistently improve the hearing deficit. We therefore recommend early implementation of hearing devices, and speech therapy, in order to save precious time, especially since the first 2 years of life are most important for speech and language development (Zumach et al. 2009).

Acknowledgements We would like to thank all patients for participating in the study, J. Hardon and R. Nelisse for their contribution to the study, and Prof. Dr. H.W. Paerl for critical review of the manuscript.

Competing interest statement and details of funding The Research on Pompe disease at Erasmus MC was financially supported by, ZonMw-Dutch organization for healthcare research and innovation of care [Grant 152001005], 7th Frame Program "EUCLYD-a European Consortium for Lysosomal Storage Diseases" of the European Union (health F2/2008 grant agreement 201678) and The 'Prinses Beatrix Fonds' [Research Award].

The authors confirm independence from the sponsors; the content of the article has not been influenced by the sponsors.

ATvdP and ARR provide consulting services for Genzyme Corp, Cambridge, MA, USA, under an agreement between Genzyme Corp and Erasmus MC, Rotterdam, the Netherlands. This agreement also caters to financial support for Erasmus MC for research in Pompe's disease. Erasmus MC and inventors for the method of treatment of Pompe's disease by enzyme replacement therapy receive royalty payments pursuant to Erasmus MC policy on inventions, patents and technology transfer.

The study was approved by the Institutional Review Board of the Erasmus Medical Center.

Open Access This article is distributed under the terms of the Creative Commons Attribution Noncommercial License which permits any noncommercial use, distribution, and reproduction in any medium, provided the original author(s) and source are credited.

\section{References}

Bamiou DE, Campbell P, Liasis A et al (2001) Audiometric abnormalities in children with Gaucher disease type 3. Neuropediatrics 32:136-141

Engel AG, Hirschhorn R et al (2004) Acid maltase deficiency. In: Nogueira I (ed) Myology. McGraw-Hill, New York, pp 1559-1586

Hajioff D, Hegemann S, Conti G et al (2006) Agalsidase alpha and hearing in Fabry disease: data from the Fabry Outcome Survey. Eur J Clin Invest 36:663-667

Hegemann S, Hajioff D, Conti G et al (2006) Hearing loss in Fabry disease: data from the Fabry outcome survey. Eur J Clin Invest 36:654-662

Jones HN, Muller CW, Lin M et al (2009) Oropharyngeal dysphagia in infants and children with infantile Pompe disease. Dysphagia, Sep 10. [Epub ahead of print]
Kaga M, Azuma C, Imamura T et al (1982) Auditory brainstem response (ABR) in infantile Gaucher's disease. Neuropediatrics 13:207-210

Kamphoven JH, de Ruiter MM, Winkel LP et al (2004) Hearing loss in infantile Pompe's disease and determination of underlying pathology in the knockout mouse. Neurobiol Dis 16:14-20

Keilmann A, Hajioff D, Ramaswami U et al (2009) Ear symptoms in children with Fabry disease: data from the Fabry outcome survey. J Inherit Met Dis 32(6):739-744

Kishnani PS, Hwu WL, Mandel H et al (2006) A retrospective, multinational, multicenter study on the natural history of infantile-onset Pompe disease. J Pediatr 148:671-676

Kishnani PS, Corzo D, Nicolino M et al (2007) Recombinant human acid [alpha] glucosidase: major clinical benefits in infantile-onset Pompe disease. Neurology 68:99-109

Kishnani PS, Corzo D, Leslie ND et al (2009) Early treatment with alglucosidase alpha prolongs long-term survival of infants with Pompe disease. Pediatr Res 66:329-335

Komura Y, Kaga K, Ogawa Y et al (1998) ABR and temporal bone pathology in Hurler's disease. Int J Pediatr Otorhinolaryngol 43:179-188

Lacey DJ, Terplan K (1984) Correlating auditory evoked and brainstem histologic abnormalities in infantile Gaucher's disease. Neurology 34:539-541

Mathew GA, Kuruvilla G, Job A (2007) Dynamic slow motion video endoscopy in Eustachian tube assessment. Am J Otolaryng 28:91-97

Palla A, Hegemann S, Widmer U et al (2007) Vestibular and auditory deficits in Fabry disease and their response to enzyme replacement therapy. J Neurol 254:1433-1442

Peck JE (1984) Hearing loss in Hunter's syndrome-mucopolysaccharidosis II. Ear Hear 5:243-246

Schachern PA, Shea DA, Paparella MM et al (1989) Otologic histopathology of Fabry's disease. Ann Otol Rhinol Laryngol 98:359-363

Schachern PA, Cureoglu S, Tsuprun V (2007) Age-related functional and histopathological changes of the ear in the MPS I mouse. Int J Pediatr Otorhinolaryngol 71:197-203

Strothotte S, Strigl-Pill N, Grunert B et al (2009) Enzyme replacement therapy with alglucosidase alfa in 44 patients with late-onset glycogen storage disease type 2: 12-month results of an observational clinical trial. J Neurol 257:91-97

Thurberg BL, Lynch Maloney C, Vaccaro C et al (2006) Characterization of pre- and post-treatment pathology after enzyme replacement therapy for Pompe disease. Lab Invest 86:1208-1220

Tos M (1998) Importance of eustachian tube function in middle ear surgery. Ear Nose Throat J 77:744-747

van Capelle CI, Winkel LP, Hagemans ML et al (2008) Eight years experience with enzyme replacement therapy in two children and one adult with Pompe disease. Neuromuscul Disord 18:447-452

van den Hout HM, Hop W, van Diggelen OP et al (2003) The natural course of infantile Pompe's disease: 20 original cases compared with 133 cases from the literature. Pediatrics 112:332-340

Van den Hout JM, Kamphoven JH, Winkel LP et al (2004) Long-term intravenous treatment of Pompe disease with recombinant human alpha-glucosidase from milk. Pediatrics 113:e448-e457

van der Ploeg AT, Reuser AJ (2008) Pompe's disease. Lancet 372:13421353

WHO (1980) International classification of impairments, disabilities and handicaps: a manual of classification related to the consequences of disease. WHO, Geneva

Winkel LP, Hagemans ML, van Doorn PA et al (2005) The natural course of non-classic Pompe's disease; a review of 225 published cases. J Neurol 252:875-884

Zumach A, Gerrits E, Chenault M et al (2009) Long-term effects of early otitis media on language development. J Speech Lang Hear Res, Jul 27 [Epub ahead of print] 